\title{
The results of Percutaneous Transcatheter Pulmonary valvuloplasty in Adult Patients
}

\author{
Zahra Khajali ${ }^{1}$, Ata Firouzi ${ }^{2}$, Homa Ghaderian ${ }^{1}$, Ehsan Khalilipour ${ }^{2}$, Maryam Aliramezany ${ }^{3}$ and Zahra Hosseini ${ }^{2 *}$ \\ ${ }^{1}$ Rajaie Cardiovascular Medical and Research Center, Iran University of Medical Sciences, Tehran, Iran \\ ${ }^{2}$ Cardiovascular Intervention Research Center, Rajaie Cardiovascular Medical and Research Center, Iran University of Medical Sciences, Tehran, Iran \\ ${ }^{3}$ Cardiovascular Research Center, Institute of Basic and Medical Physiology Science, University of Medical Science, Kerman, Iran
} Submission: May 07, 2021; Published: May 26, 2021

*Corresponding author: Zahra Hosseini, Assistant professor of Interventional Cardiology, Cardiovascular Intervention Research Center, Rajaie Cardiovascular Medical and Research Center, Iran University of Medical Sciences, Vali-Asr Ave, Tehran, Iran

\section{Abstract}

Background: Pulmonary valve stenosis (PS) is a rare congenital heart disease in adults. Commissural fusion and narrowing of the central lumen are the basic pathology in valvular PS.

Methods: This trial is a retrospective observational cohort study which is performed from 2011 to 2020 in 107 adult patients with congenital pulmonary valve stenosis, who were referred to Rajaie Cardiovascular Medical and Research Center, the largest referral center for congenital heart disease in adults in Iran. Procedural technique, immediate and up to one year follow-up of these patients, and the definition of successful intervention are described.

Results: A total of 107 patients underwent percutaneous transcatheter pulmonary commissurotomy (PTPC). The mean age was $33.1 \pm 12.8$ years (18-79 years), of whom 46 (43\%) were male. More than half of the patients $(62.6 \%)$ had NYHA functional class $\geq$ II before the intervention. The peak gradient of pulmonary valve (PVPG) decreased from $91 \pm 34.7 \mathrm{mmHg}$ at baseline to $38.9 \pm 16.1 \mathrm{mmHg}$ immediately post valvuloplasty ( $p=0.032$ ). The right ventricular systolic pressure (RVSP) decreased from $115.9 \pm 34.1 \mathrm{mmHg}$ at baseline to $59.2 \pm 20.1 \mathrm{mmHg}$ post procedure ( $p<0.001)$. Successful PTPC, based on transvalvular gradient $(\leq 25 \mathrm{mmHg})$, was confirmed in 90 (85\%) patients whereas when based on RVSP reduction $>50 \%$, the percentage of success rate was reduced to $42(40 \%)$ of patients. The success rate after one year follow-up was $92.5 \%$. After one year follow-up only 8 (7.5\%) patients did not respond to PTPC (PVPG $>25 \mathrm{mmHg}$ ), of whom, about $4.5 \%$ had dysplastic valves and $3 \%$ had severe infundibular hypertrophy respectively. Also, in subgroup analysis we compared patients in two groups based on the RVSP reduction and transvalvular gradient.

Conclusion: The PTPC is a safe and efficient procedure in adult patients with severe pulmonary valve stenosis. Irrespective of sub-valvular gradient, in majority of cases, the gradient would be decreased significantly during one-year follow-up after PTPC ( $92.5 \%$ in this study). The use of beta blockers in patients with infundibular hypertrophy could reduce the gradient dramatically; in such a way that after 1 year the degree of residual gradient is minimal; so, we demonstrated that if the successful criteria in adult patients after PTPC being just only on the RVSP reduction $>50 \%$, it would lead to underestimation of effectiveness of PTPC; so, we suggest that the best criteria of successful PTPC in adult patients is post procedure peak systolic valvular gradient $<25 \mathrm{mmHg}$.

\section{Introduction}

Congenital isolated pulmonary valve stenosis (PS) accounts for $5-10 \%$ of all congenital heart disease [1]. In most of the cases, the stenosis is due to fusion of commissures leading to "doming" of the valve leaflets with a narrow central opening but a preserved mobile valve base. In the presence of normal RV function and normal transvalvular flow, PS is considered mild when the peak gradient across the obstruction is $<36 \mathrm{mmHg}$, moderate if $36-64$ $\mathrm{mmHg}$, and severe when the gradient is $>64 \mathrm{mmHg}$. The severity of the symptoms in adult patients is depended on the degree of the valvular stenosis, any evidence of sub-valvular or peripheral stenosis, the severity of the right ventricle dysfunction, tricuspid regurgitation, and any concomitant defects such as ASD or VSD. In those with isolated mild PS who are usually asymptomatic, the disease is not progressive; moderate PS can progress at the valvular or sub-valvular level because of compensatory myocardial hypertrophy and those ones with severe PS commonly present with exertional dyspnea, chest pain, palpitation, cyanosis, syncope, and in advanced cases would display signs and symptoms of advanced RV failure. In those with moderate to severe type, intervention is usually required for improving their symptoms [2]. 
After the first successful percutaneous transcatheter pulmonary commissurotomy (PTPC) by Kan et al in 1982, this procedure replaced the surgical method and nowadays, is the preferred method of treatment in these patients regardless of age and valve morphology [3]. This method consistently affords safe and dramatic improvement of the valvular obstruction, and has also less trauma and an equivalent sustained gradient relief when compared to surgical intervention. Numerous studies have been performed to evaluate the success rate of the PTPC, but the longterm studies are lacking.

Based on the previous studies the definition of successful procedure was transvalvular gradient less than $30 \mathrm{mmHg}$ with no more than moderate pulmonary regurgitation. In this study, immediate success was defined as post procedure peak systolic valvular gradient $<25 \mathrm{mmHg}$ or decrease in right ventricular systolic pressure (RVSP) by 50\%; all hemodynamic data were measured immediately after the procedure through an end-hole catheter [4].

The aim of this retrospective cohort study that consecutively recruited 107 adult patients with congenital pulmonary valve stenosis, is to evaluate the short and mid-term outcomes of this procedure, present a new definition of successful PTPC in adults and the factors, which are associated with procedural failure.

\section{Methods}

This retrospective observational cohort study was performed from 2011 to 2020 in 107 adult patients with congenital pulmonary valve stenosis, who were referred to Rajaie Cardiovascular Medical and Research Center, the largest referral center for congenital heart disease in adults in Iran. The inclusion criteria were all patients over 18 years of age with isolated congenital pulmonary valve stenosis, who trans-pulmonary gradient at the valvular level on trans-thoracic echocardiography was more than $50 \mathrm{mmHg}$ or those who were symptomatic. Furthermore, patients with concomitant heart defects such as ASD, PFO or PDA were also included in this study, if they were not hemodynamically significant. Patients with stenosis at a level other than the valve or those with concomitant heart defects which required surgery or restenosis in patients with a history of open-heart surgery were excluded. The local ethics committee of Rajaie Cardiovascular, Medical and Research Center, Iran University of Medical Sciences, approved the trial design and a written informed consent was obtained from patients before the procedure.

Demographic information was recorded and clinical symptoms of all patients were classified according to the New York Heart Association (NYHA) functional class [5].

Transthoracic echocardiography was performed by Philips EPIQ 7C machine in left supine position. Right ventricular systolic and diastolic function were evaluated by tricuspid annular plane systolic excursion (TAPSE), right ventricular peak systolic velocity (Tissue Doppler), and fractional area change (FAC). RV size, thickness, and the severity of the transvalvular gradient was measured by PW, and precise assessment was performed to rule out any evidence of sub-valvular stenosis (DCRV), supra-valvular, and peripheral stenosis or any other defects or anomalies (ASD, VSD, PFO, single ventricle). At the level of pulmonary valve, hinge to hinge measurement of the annulus diameter at systole was estimated; also, the morphology of the PV including the valve thickness, calcification severity, and any dysplastic changes were described.

\section{Procedural Technique}

After insertion of 2 femoral arterial and venous short sheaths (6 F), cardiac catheterization with measurements of left ventricular end diastolic pressure, right ventricular systolic pressure, right ventricular end diastolic pressure, mean pulmonary artery pressure, and pulmonary capillary wedge pressure, were performed under local anesthesia and RV injection in AP and lateral projections were performed; on fluoroscopy the hinge-to-hinge annulus diameter was measured to choose the balloon size about $110-140 \%$ of annulus size, and the appropriate balloon was chosen. After crossing the PV with 0.035 inch $260 \mathrm{~cm}$ long guide wire, over which Pigtail catheter was tracked, the wire was replaced with $0.035 \mathrm{inch}$ Amplatzer Super-stiff $260 \mathrm{~cm}$ long guide wire positioned in LPA, and after adjusting the balloon position in the lateral view, the balloon was inflated with diluted contrast by PTMC syringe, until the waist disappeared. The most important issue in this step is stabilizing the balloon in its position and avoiding any slippage. Each inflation - deflation time should not be taken more than 10 seconds with close hemodynamic monitoring. After the procedure, using a Multipurpose catheter, the final pulmonary artery pressure, trans-valvular gradient, sub-valvular gradient, and RVSP were measured; if the residual transvalvular gradient was more than $25 \mathrm{mmHg}$, the procedure of balloon dilation was repeated with higher pressure inflation (it can be repeated up to eight times) or with larger balloons or double balloon technique; when the transvalvular gradient was acceptable and immediate success criteria was achieved, irrespective of the severity of sub-valvular gradient, all patients were followed up medically.

\section{Statistical Analysis}

Continuous variables were presented as mean \pm SD or median (interquartile range), and categorical variables were expressed as number (percentage). The chi-squared test or the Fisher's exact test was implemented to compare categorical variables between groups as appropriate. Continuous variables were compared between the defined groups using t-test or Mann-Whitney U test as appropriate. The changes in the grading of study variables during follow-up period (i.e., baseline, immediately postoperative, 6 months, and 1 year) were performed using the paired t-test, the general linear model repeated measures, and the Cochran's $Q$ test, as appropriate. The Bonferroni test was also used to compare variable in different intervals. A two-sided p-value was reported. All statistical analyses were performed using SPSS software (IBM, Armonk, NY, USA). 


\section{Results}

\section{Baseline characteristics}

A total of 107 patients underwent PTPC, the mean age was $33.1 \pm 12.8$ years (18-79 years), of whom 46 (43\%) were male. More than half of the patients $(62.6 \%)$ had NYHA functional class $\geq$ II before the intervention. Most (70\%) had mild to moderate RV enlargement and dysfunction (85\%). The most commonly used balloon diameter and length were 24 and $40 \mathrm{~mm}$ respectively. Other baseline characteristics are shown in Table 1.

Table 1: Baseline demographic features of patients.

\begin{tabular}{|c|c|}
\hline Variables & Values $\mathrm{N}(/ \%)$ \\
\hline Age, year & $33.1 \pm 12.8$ \\
\hline Male & $46(43)$ \\
\hline Annulus size, mm & $1.8(1.8-1.9)$ \\
\hline Balloon length size, mm & 40 (40 to 50$)$ \\
\hline Balloon diameter size, $\mathrm{mm}$ & 24 (18 to 28$)$ \\
\hline \multicolumn{2}{|l|}{ NYHA functional class } \\
\hline I & $40(37.4)$ \\
\hline II & $58(54.2)$ \\
\hline III & $9(8.4)$ \\
\hline \multicolumn{2}{|l|}{ TR Grading } \\
\hline Mild & $63(58.9)$ \\
\hline Moderate & $39(36.4)$ \\
\hline Severe & $5(4.5)$ \\
\hline \multicolumn{2}{|l|}{ RV Enlargement } \\
\hline Mild & $36(33.6)$ \\
\hline Moderate & $49(45.4)$ \\
\hline Severe & $22(20)$ \\
\hline \multicolumn{2}{|l|}{ RV dysfunction } \\
\hline Mild & $55(51.4)$ \\
\hline Moderate & $36(33.6)$ \\
\hline Severe & $16(14.9)$ \\
\hline \multicolumn{2}{|l|}{ RVH } \\
\hline Mild & $21(19.6)$ \\
\hline Moderate & $32(29.9)$ \\
\hline Severe & $55(51.4)$ \\
\hline Post-stenotic dilatation & $50(47)$ \\
\hline Infundibular Hypertrophy & $37(34.5)$ \\
\hline SPAP, mmHg & $23.6 \pm 6.9$ \\
\hline RVSP, mmHg & $115.9 \pm 34.1$ \\
\hline PVPG, mmHg & $91 \pm 34.7$ \\
\hline
\end{tabular}

Data are presented as mean $\pm \mathrm{SD}$, median (interquartile range), or number (percentage)

NYHA = New York heart association; PBV = balloon pulmonary valvuloplasty; $\mathrm{RV}=$ right ventricle; $\mathrm{RVH}=$ right ventricular hypertrophy; RVSP = right ventricular systolic pressure; SPAP = systolic pulmonary arterial pressure; TR = tricuspid valve regurgitation.

\section{Procedural Outcomes}

The peak gradient of pulmonary valve (PVPG) decreased from $91 \pm 34.7 \mathrm{mmHg}$ at baseline to $38.9 \pm 16.1 \mathrm{mmHg}$ immediately post valvuloplasty $(\mathrm{p}=0.032)$. The right ventricular systolic pressure (RVSP) decreased from $115.9 \pm 34.1 \mathrm{mmHg}$ at baseline to $59.2 \pm$ $20.1 \mathrm{mmHg}$ post procedure ( $\mathrm{p}<0.001$-Table 2 ). When we compared among genders, pre-and-post-interventional values were not significantly different for PVPG and RVSP. Successful PTPC, based on transvalvular gradient ( $\leq 25 \mathrm{mmHg}$ ), was confirmed in 90 (84\%) patients whereas when based on RVSP reduction $>50 \%$, the percentage of success rate was reduced to $42(40 \%)$ of patients. In 65 patients in whom the RVSP reduction was $<50 \%$, the immediate transvalvular gradient was measured at valve and subvalvular region and showed that in $42(65 \%)$ of the patients, the transvalvular gradient was less than $25 \mathrm{mmHg}$ and in the rest, it was more than $25 \mathrm{mmHg}$. In these 23 patients, PTPC was repeated with larger balloons (gradually increased the ballooning size up to $1.4: 1$ ) and the transvalvular and sub-valvular gradient was measured again. Of these, 6 patients had trans-valvular gradient less than $25 \mathrm{mmHg}$, whilst in the remaining 17 patients, the transvalvular gradient remained high. These patients, regardless of infundibular gradients, were followed up medically. After one year follow-up in these 17 patients, 9 achieved successful criteria (PVPG $<25 \mathrm{mmHg}$ ) and only 8 (7.5\%) patients did not respond to PTPC (PVPG $>25 \mathrm{mmHg}$ ), of whom, about $4.5 \%$ had dysplastic valves and $3 \%$ had severe infundibular hypertrophy respectively (Table 2).

Hemodynamic and clinical features were compared at intervals (at baseline, immediately after the procedure, at 6 months, and at 1 year). The changes in PVPG level were significantly different at four interval measurements $(p<0.001)$. Changes in functional class and RV function were also significantly different within 1 year follow-up (both had $\mathrm{p}<0.001$ ). The same results were observed for RV hypertrophy ( $p<0.001)$, RV size ( $<<0.001)$, and tricuspid valve regurgitation severity $(\mathrm{p}<0.001)$. All mentioned parameters showed steady decrease in grading across intervals, from baseline to 1-year follow-up (Table 2).

\section{Subgroups analysis}

We compared baseline characteristics between patients whom immediately have reduced RVSP and whom the RVSP not reduced more than $50 \%$. We compared the 42 patients who responded to PTPC according to RVSP reduction ( $>50 \%$ ) as a responder group or group 1 with the rest of the patients (65) who had higher RVSP (less than $50 \%$ reduction) as a non-responder group or group 2 . The mean age and the number of male patients were comparable between the groups. The post-procedure PVPG was significantly lower in responder group in compared with non-responder group $(37.2 \pm 16.9$ versus $44.8 \pm 16.6 \mathrm{mmHg}$, respectively, $\mathrm{p}=0.039)$. The RVSP immediately after the procedure was also lower in group 1 in comparison to the group 2 (51.4 \pm 15.3 versus $72.3 \pm 15.1 \mathrm{mmHg}$, respectively, $\mathrm{p}<0.001)$. The baseline transvalvular gradient was also significantly lower in group 1 compared with group 2 (38.6 \pm 15 versus $51.4 \pm 21.4 \mathrm{~mm} \mathrm{Hg}$, respectively, $\mathrm{p}=0.012$, Table 3 ). 
Table 2: Total results immediately post procedure, at 6 months, and at 1 year follow-up.

\begin{tabular}{|c|c|c|c|}
\hline Parameters & Before the procedure & After the procedure & P value \\
\hline Immediate PVPG & $91 \pm 34.7$ & $38.9 \pm 16.1 \mathrm{mmHg}$ & $\mathrm{p}=0.032$ \\
\hline Improvement in PVPG at 6 months follow-up & - & - & $<0.001$ \\
\hline Improvement in PVPG at 1 year follow-up & - & - & $<0.001$ \\
\hline RVSP & $115.9 \pm 34.1$ & $59.2 \pm 20.1 \mathrm{mmHg}$ & $\mathrm{P}<0.001$ \\
\hline SPAP & $23.6 \pm 6.9$ & $22 \pm 4.5$ & $\mathrm{P}=0.8$ \\
\hline IIII & $<0.001$ \\
\hline Improvement in functional class at 1 year follow-up & Moderate to severe & Mild to moderate & $<0.001$ \\
\hline Improvement in RV function at 1 year follow-up & Moderate to severe & Mild to moderate & $<0.001$ \\
\hline Improvement in RV size at 1 year follow-up & Moderate to severe & Mild to moderate & $<0.001$ \\
\hline Improvement in TR severity at 1 year follow-up & Moderate to severe - & Mild to moderate & $<0.001$ \\
\hline
\end{tabular}

Data are presented as mean $\pm S D$, median (interquartile range), or number (percentage)

$\mathrm{PVPG}=$ pulmonary valve peak RVSP = right ventricular systolic pressure; SPAP = systolic pulmonary arterial pressure.

Table 3: Comparing characteristics items between two groups based on RVSP reduction $>50 \%$.

\begin{tabular}{|c|c|c|c|}
\hline \multirow{3}{*}{ Variables } & RVSP reduction & RVSP non reduction & \multirow{3}{*}{ P-value } \\
\hline & $(n=42)$ & $(n=65)$ & \\
\hline & $40 \%$ & $60 \%$ & \\
\hline Age, year & $33.5 \pm 12.8$ & $37 \pm 12.9$ & 0.65 \\
\hline Male & $35(83 \%)$ & $40(61 \%)$ & 0.1 \\
\hline Annulus size, $\mathrm{cm}$ & $2(1.8-2.4)$ & $1.8(1.7-2)$ & 0.2 \\
\hline Balloon length, mm & $40(40-50)$ & $40(40-50)$ & \\
\hline Balloon diameter size, $\mathbf{m m}$ & $24(20-28)$ & $24(18-26)$ & 0.8 \\
\hline \multicolumn{4}{|l|}{ Balloon brands } \\
\hline Zelos & $6(14 \%)$ & $30(46 \%)$ & \\
\hline BIB & $9(21 \%)$ & $7(10 \%)$ & \\
\hline NUCLEOUS & $5(12 \%)$ & $2(3 \%)$ & \\
\hline TYSHAK & $2(5 \%)$ & $2(3 \%)$ & \\
\hline CRISTAL & $7(16 \%)$ & $10(15 \%)$ & \\
\hline ATLAS & $8(19 \%)$ & $10(15 \%)$ & \\
\hline VACSII & $0(0 \%)$ & 0 & \\
\hline OPTIMED & $5(12 \%)$ & $4(6 \%)$ & \\
\hline MULLINS & $0(0 \%)$ & 0 & \\
\hline NYHA Functional class & & & 0.018 \\
\hline $\mathbf{I}$ & $23(54 \%)$ & $20(30 \%)$ & \\
\hline II & $17(40 \%)$ & $38(60 \%)$ & \\
\hline III & $2(5 \%)$ & $7(10 \%)$ & \\
\hline TR Severity & & & $<0.07$ \\
\hline Mild & $31(73 \%)$ & $32(50 \%)$ & \\
\hline
\end{tabular}




\begin{tabular}{|c|c|c|c|}
\hline Moderate & $9(21 \%)$ & $30(46 \%)$ & \\
\hline Severe & $2(5 \%)$ & $3(4 \%)$ & \\
\hline RV size & & & 0.8 \\
\hline Mild & $11(26 \%)$ & $25(38 \%)$ & \\
\hline Moderate & $24(57 \%)$ & $25(50 \%)$ & \\
\hline severe & $7(16 \%)$ & $15(12 \%)$ & \\
\hline $\mathrm{RV}$ dysfunction & & & 0.8 \\
\hline Mild & $31(73.8 \%)$ & $24(36 \%)$ & \\
\hline Moderate & $7(16.6 \%)$ & $29(44 \%)$ & \\
\hline Severe & $4(10 \%)$ & $12(18 \%)$ & \\
\hline RVH & & & 0.4 \\
\hline mild & $18(42 \%)$ & $3(6 \%)$ & \\
\hline moderate & $14(35 \%)$ & $18(27 \%)$ & \\
\hline severe & $10(23 \%)$ & $44(67 \%)$ & \\
\hline Post-stenotic dilatation & $20(47 \%)$ & $30(46 \%)$ & 0.3 \\
\hline Infundibular hypertrophy & $47.20 \%$ & $62.90 \%$ & 0.07 \\
\hline SPAP, mmHg & $25 \pm 7$ & $23 \pm 5$ & 0.4 \\
\hline RVSP (Immediately) & $51.4 \pm 15.3$ & $72 \pm 15$ & $<0.001$ \\
\hline RVSP (During 6 months F/U) & $45 \pm 10$ & $68 \pm 20$ & $<0.01$ \\
\hline RVSP (During 1 year F/U) & $40 \pm 15$ & $53 \pm 15$ & 0.6 \\
\hline PVPG (Immediately) & $37.2 \pm 16.9$ & $44.8 \pm 16$ & 0.039 \\
\hline PVPG (During 6 months F/U) & $31.1 \pm 12.6$ & $40.4 \pm 12$ & 0.04 \\
\hline PVPG (During 1 year F/U) & $30.9 \pm 15$ & $36.6 \pm 15$ & 0.6 \\
\hline Dysplastic PS & $0(0 \%)$ & $5(4.5 \%)$ & \\
\hline
\end{tabular}

The majority of patients (63\%) in the group 2 had significant infundibular gradient, but the gradient severity at the valvular level were comparable with group 1 after several attempts of balloon dilatations.

During 6months follow-up, the number of patients with improved functional class was comparable between two groups (20.8\% versus $29 \%, p=0.367$ ). However, the number of patients with functional class I or more, during 1-year follow-up was significantly lower in the group 1 ( $45 \%$ versus $70 \%, p=0.018$ ). The degree of RV dysfunction based on echocardiography findings was comparable between 2 groups in 6 months and 1-year follow-up period. Moreover, the PVPG at 6-month follow-up was significantly lower in the group 1 in comparison with the group 2 (31.1 \pm 12.6 versus $40.4 \pm 12 \mathrm{mmHg}$, respectively, $\mathrm{p}=0.040$ ). However, the PVPG at 1-year follow-up was similar between the groups (30.9 \pm 15 versus $36.6 \pm 15 \mathrm{~mm} \mathrm{Hg}$, respectively, $\mathrm{p}=0.62$ ). Based on the one-way repeated measured analysis of variance for the PVPG changes from baseline to 1-year follow-up (baseline, early postoperative, 6 months, and 1 year), tests for within-subject effects were significant among both groups $(\mathrm{p}<0.001)$.

Our study has been shown that patients in group 2 had higher baseline RVSP and transpulmonary valve gradient, and also had more degree of RVH (RV free wall thickness more than $5 \mathrm{~mm}$ by echocardiography), infundibular hypertrophy and gradient relative to group 1. At one-year follow-up, PVPG in 99 (92.5\%) patients decreased significantly and RVH regressed (RV free wall thickness less than $5 \mathrm{~mm}$ ), and only in 8 patients PVPG remained at higher level, of whom, 5 patients had dysplastic valves and 3 patients had severe dynamic infundibular hypertrophy, which required surgical treatment after failed transcatheter intervention (Table 3). The frequency of complications at followup was comparable between the groups (0\% vs. $6.8 \%$ in group 1 and group 2 , respectively $(\mathrm{p}=0.114)$. Of 8 patients in the group 2 , five had dysplastic valves and finally we remarked these 8 patients as an unsuccessful group and compared them with another 99 patients as a successful group in another subgroup analysis, the 
baseline characteristics of successful and unsuccessful groups are showed in Table 4. During follow-up, no patients in the successful group developed valve restenosis. In $80 \%$ of patients, on the day after PTPC, pulmonary regurgitation appeared or increased by one degree in severity, and on one-year follow-up, only five patients had more than moderate pulmonary regurgitation.

Table 4: Comparing characteristics items between groups based on successful PTPC (Transvalvular gradient $<25 \mathrm{mmHg}$ ).

\begin{tabular}{|c|c|c|c|}
\hline Variables & Successful PTPC $(n=99)$ & Unsuccessful PTPC (n=8) & P-value \\
\hline Total patients with $\mathrm{PVPG}<25 \mathrm{mmHg}$ after 1 year & 99 (92.5\%) & $8(7.5 \%)$ & \\
\hline Age, year & $33.5 \pm 12.8$ & $32 \pm 12.9$ & 0.65 \\
\hline Male & $35(35 \%)$ & $5(62.5 \%)$ & 0.2 \\
\hline Annulus size, $\mathrm{cm}$ & $2(1.8-2.2)$ & $1.8(1.7-2)$ & 0.3 \\
\hline Balloon length, mm & $40(40-50)$ & $40(40-50)$ & \\
\hline Balloon diameter size, $\mathrm{mm}$ & $24(20-28)$ & $24(18-26)$ & \\
\hline \multicolumn{4}{|l|}{ Balloon brands } \\
\hline Zelos & $40(40 \%)$ & 0 & \\
\hline BIB & $22(22 \%)$ & $3(37.5 \%)$ & \\
\hline NUCLEOUS & $5(5 \%)$ & 0 & \\
\hline TYSHAK & $4(4 \%)$ & 0 & \\
\hline CRISTAL & $10(10 \%)$ & $3(37.5 \%)$ & \\
\hline ATLAS & $9(9 \%)$ & $2(25 \%)$ & \\
\hline VACSII & $3(3 \%)$ & 0 & \\
\hline OPTIMED & $7(7 \%)$ & 0 & \\
\hline MULLINS & 0 & 0 & \\
\hline \multicolumn{4}{|l|}{ NYHA Functional class } \\
\hline I & $39(39 \%)$ & $1(12 \%)$ & $<0.018$ \\
\hline II & $54(54 \%)$ & $4(50 \%)$ & \\
\hline III & $6(7 \%)$ & $3(37 \%)$ & \\
\hline TR severity & & & 0.3 \\
\hline Mild & $61(61 \%)$ & $2(25 \%)$ & \\
\hline Moderate & $35(35 \%)$ & $4(50 \%)$ & \\
\hline Severe & $3(4 \%)$ & $2(25 \%)$ & \\
\hline RV size & & & 0.2 \\
\hline Mild & $33(33 \%)$ & $3(37.5 \%)$ & \\
\hline Moderate & $46(47 \%)$ & $3(37.5 \%)$ & \\
\hline severe & $20(20 \%)$ & $2(25 \%)$ & \\
\hline RV dysfunction & & & 0.4 \\
\hline Mild & $34(34 \%)$ & $2(25 \%)$ & \\
\hline Moderate & $53(53 \%)$ & $3(37.5 \%)$ & \\
\hline Severe & $12(13 \%)$ & $3(37.5 \%)$ & \\
\hline Post-stenotic dilatation & $47(47 \%)$ & $3(37.5 \%)$ & \\
\hline Infundibular hypertrophy & $32(32 \%)$ & $5(62.5 \%)$ & $<0.01$ \\
\hline SPAP, mmHg & $23 \pm 6.9 \mathrm{mmHg}$ & $23 \pm 5 \mathrm{mmHg}$ & 0.7 \\
\hline RVSP, mmHg & $50 \pm 10 \mathrm{mmHg}$ & $70 \pm 10 \mathrm{mmHg}$ & 0.01 \\
\hline PVPG (Immediately) & $25 \pm 8 \mathrm{mmHg}$ & $65 \pm 15 \mathrm{mmHg}$ & $<0.01$ \\
\hline
\end{tabular}




\begin{tabular}{|c|c|c|c|}
\hline PVPG (During 6 months F/U) & $25 \pm 5 \mathrm{mmHg}$ & $55 \pm 10 \mathrm{mmHg}$ & $<0.01$ \\
\hline PVPG (During 1 year F/U) & $20 \pm 8 \mathrm{mmHg}$ & $50 \pm 10 \mathrm{mmHg}$ & $<0.01$ \\
\hline
\end{tabular}

The success rate of PTPC during one-year follow-up in this single center study was $92.5 \%$ and $7.5 \%$ patients required surgical valve replacement. We had one case of pulmonary artery dissection and one case of early endocarditis which were managed medically.

\section{Discussion}

Isolated pulmonary valve stenosis is a common congenital heart disease and most of them are detected during childhood. Until 1982, surgical valvotomy was the traditional method of treatment, when Kan et al. reported the technique of percutaneous valvuloplasty [6]. PTPC has been reported as an effective and safe procedure with high success rate for treatment of severe pulmonary valve stenosis in adult patients with sustainable immediate, short, mid-term and long-term outcomes $[7,8]$. Several trials have demonstrated the efficacy and feasibility of this procedure in adults [9], so PTPC is a good alternative to surgery with acceptable long-term results.

In our study, among 107 adult patients, 92.5\% had eventually successful procedure at 1 year follow-up. As our patients were those with longstanding PS with associated severe infundibular hypertrophy, and large annulus size, we performed the procedure more conservatively. The initial chosen balloon/annulus ratio was $1.2: 1$ which about $85 \%$ of patients had immediate successful results (transvalvular gradient $<25 \mathrm{mmHg}$ ), but in those in whom the goal of successful result was based on $>50 \%$ RVSP reduction, only $40 \%$ of patients achieved this. Around $66 \%$ of these had transvalvular gradient less than $25 \mathrm{mmHg}$ (despite of high RVSP) and about $9 \%$ had trans-valvular gradient $<25 \mathrm{mmHg}$ after sequential balloon dilatation (with a ratio of up to 1.4/1). At oneyear follow-up, another 9 (13.5\%) patients had reduction in RVSP and PVPG. Therefore, it seems that in adult patients with severe valvular PS, the definition of successful PTPC, regarding to the more severe sub-valvular hypertrophy in comparison to children is based on transvalvular gradient and not the percentage of RVSP reduction.

Among 17 patients who did not respond to PTPC with elevated PVPG, 8 patients needed surgical procedure. In the other 9 patients, who responded during follow-up, there was regression of the infundibular hypertrophy, which contributed to the initial residual gradient.

In the unsuccessful group (8 patients), who at 1-year follow-up had higher RVSP (117.5mmHg), dramatically more infundibular hypertrophy, dysplastic valve, and astounding immobile valve were illustrated, so eventually all of them underwent surgical procedure. Previous studies have shown that because of impaired mobility of the dysplastic pulmonary valve, surgery is the preferred treatment [10]. In our study, among the 8 failed procedures, 5 $(4.5 \%)$ had dysplastic pulmonary valves (Figure 1A \& B); three of eight patients had immobile leaflet but not dysplastic valves combined with severe infundibular hypertrophy (Figure 2A, B) who underwent PV commissurotomy and infundibular resection.

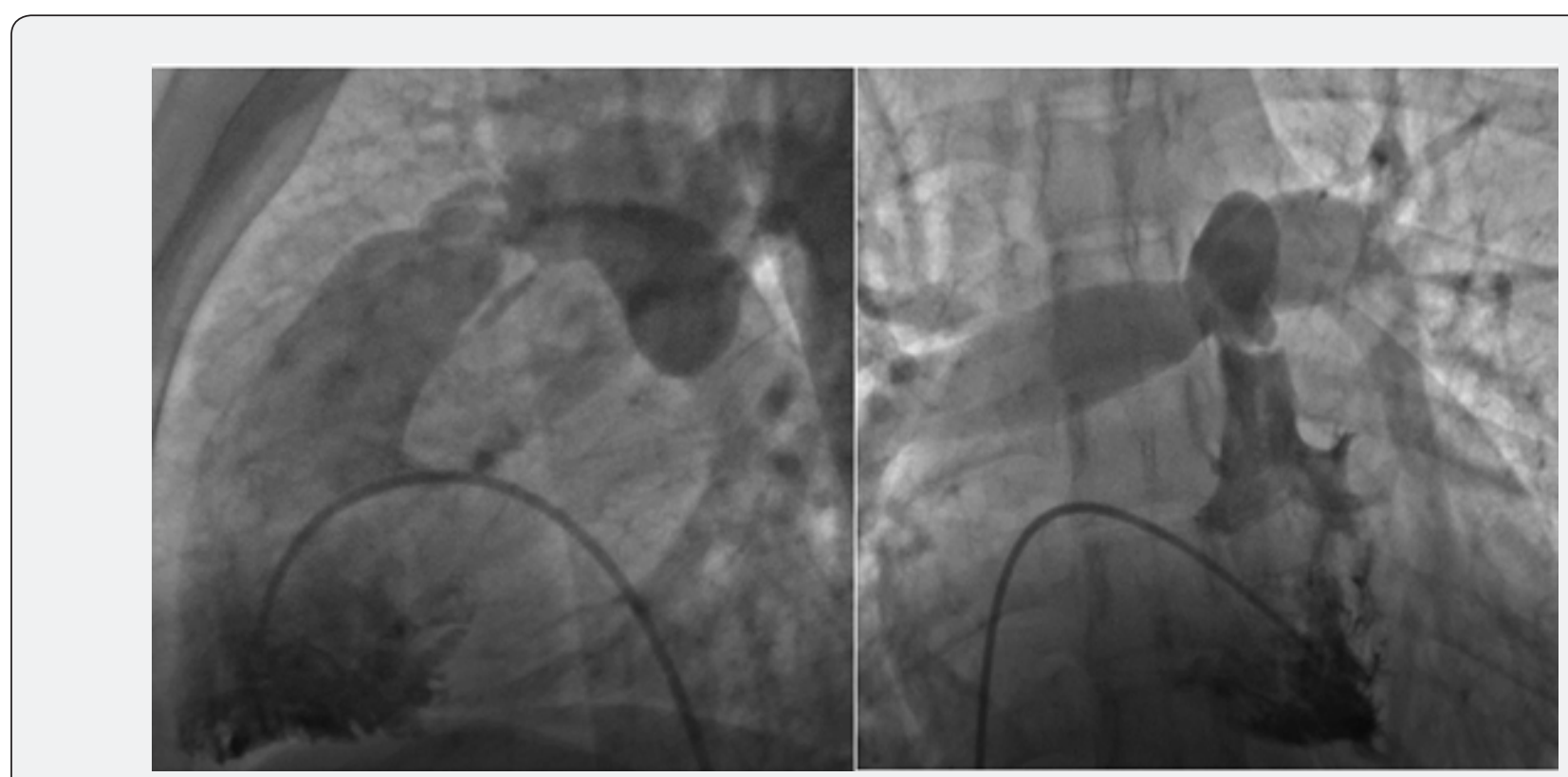

Figure 1 (A, B): In both AP and lateral projections, thick, fleshy, deformed, and dysplastic pulmonary valves are illustrated. 


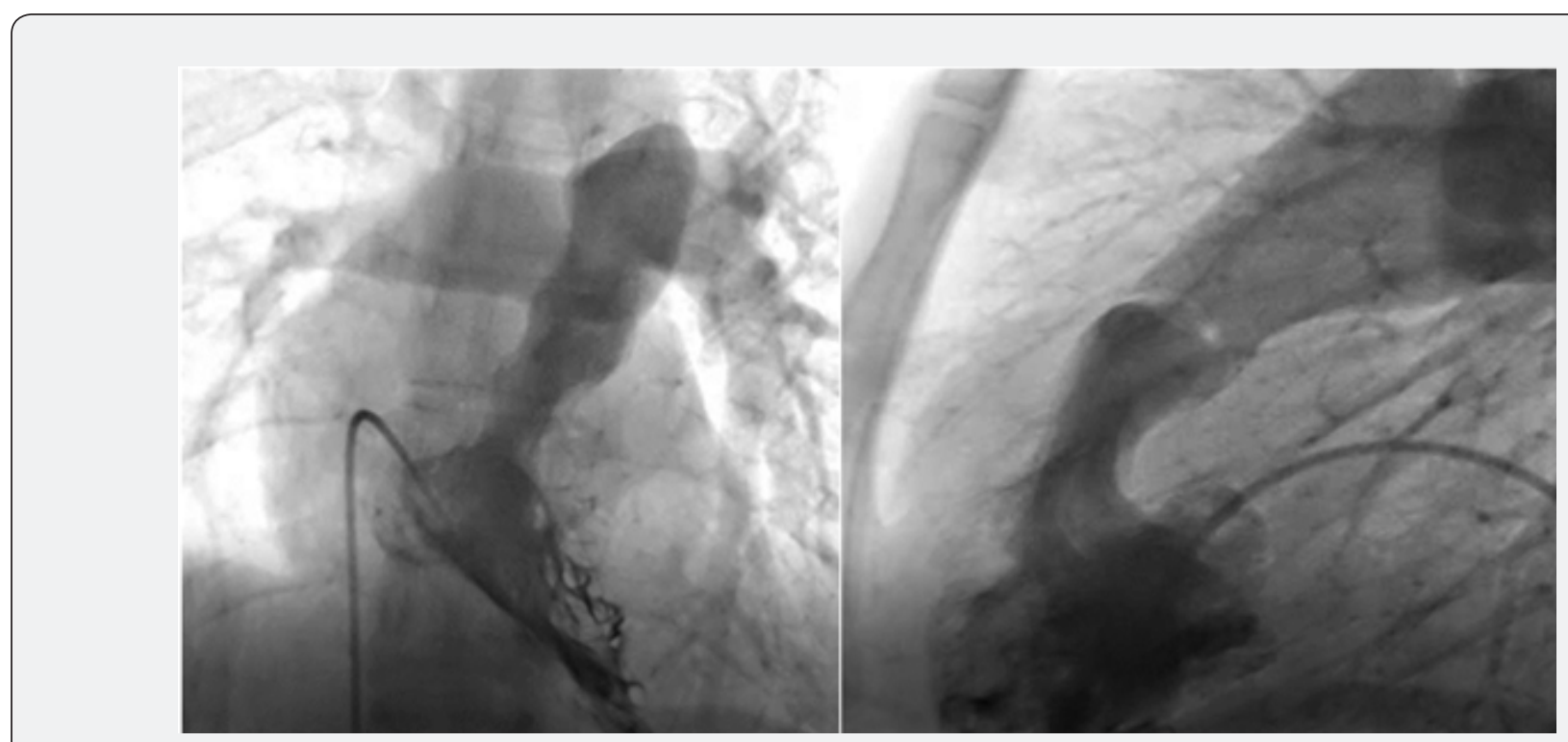

Figure 2 (A, B): Both figures showed significant infundibular hypertrophy in AP and lateral projections.

PS may also be associated with a combination of infundibular hypertrophy and post stenotic dilation. These are frequently seen in older patients with longstanding PS and those with higher degree of valvular stenosis [11]. Post stenotic dilation and infundibular hypertrophy are more frequently seen in the nonreduced RVSP group or group 2 (47.2\% and $62.9 \%$ respectively) but $\mathrm{p}$ value was not significant because of small sample size. Some studies have been shown that this hypertrophy may regress after surgical valvotomy [12]. Long-term and mid-term studies have illustrated that this complication of severe and longstanding stenosis in adults may improve after successful PTPC [13,14].

Beta blockers administered for the unsuccessful group with high RVSP, in whom the gradient had fallen but did not meet the successful criteria definition, were followed for 1-month, 6-month and 1-year. After this period, the gradient had improved. In one study, the use of beta blockers in those with significant infundibular stenosis after the procedure reduced the gradient within 3-6 months [15]. In our study, infundibular hypertrophy was common in the unsuccessful group compared with the successful group, but it was not statistically significant. The use of beta blockers in both groups with infundibular stenosis following the procedure for 1 year decreased the peak gradient of pulmonary out flow and after 1year follow up, this gradient was not noticeable in both groups. This finding showed that the use of beta blockers in adult patients with severe PS and infundibular hypertrophy would further reduce the gradient and is accompanied with better NYHA functional class.

We recommend that in adult patients with severe valvular PS and significant infundibular hypertrophy, the successful criteria after PTPC should be changed and precise gradient measurement at valvular and infundibular level should be obtained by pulling back an end-hole catheter after the procedure for confirming the success of the procedure.

A long-term study by Fawzy et al. [13] showed that severe TR regressed after successful PTPC, and our mid-term study also confirmed this, even in patients who did not meet the criteria for successful PTPC after 1 year follow up. One study of Blom et.al showed the rapid improvement of RV systolic function but delayed improvement of RV diastolic function because of the delayed regression in RV mass [16]. In our study after 1 year follow up, the degree of RV hypertrophy regression was significant after successful PTPC ( $p<00.1)$ also for RV size. Another study showed that pulmonary regurgitation in PS patients after PTPC might lead to reduced exercise capacity [17]. In our study only five patients had significant pulmonary regurgitation after PTPC and none of them need PVR.

\section{Complications}

Several studies and case reports have reported rare complications of PTPC such as pulmonary edema in elderly patients [18]. Other rare complications reported in studies include seizure, cardiac arrest, cerebrovascular accident, balloon rupture, RVOT perforation, pulmonary artery dissection, endocarditis, pericardial effusion which usually has a benign coarse and rupture of tricuspid valve papillary muscle $[11,19]$. In our study, we had one case of pulmonary artery dissection and one case of endocarditis; both of them were managed medically.

\section{Study Limitation}

Although we have illustrated a satisfactory result of PTPC in adult patients with severe pulmonary valve stenosis, our study has some limitations. It is an observational retrospective cohort 
study, and the role of bias should be considered. Also, our follow up duration was limited to 1 year. More long-term outcome studies are mandatory for more better understanding about the pathophysiology of this disease and more randomized trials for comparing the transcatheter approach versus surgical treatment in these patients.

\section{Conclusion}

The PTPC is a safe and efficient procedure in adult patients with severe pulmonary valve stenosis. The infundibular hypertrophy is more common in adult patients who had long term severe PS; so, irrespective of sub-valvular gradient (either in successful or non-successful groups), in majority of cases, the gradient would be decreased significantly during one year follow-up after PTPC (92.5\% in this study). The use of beta blockers in patients with infundibular hypertrophy could reduce the gradient dramatically; in such a way that after 1 year the degree of residual gradient is minimal; so, we demonstrated that if the successful criteria in adult patients after PTPC being just only on the RVSP reduction $>50 \%$, it would lead to underestimation of effectiveness of PTPC; so, we suggest that the best criteria of successful PTPC in adult patients is post procedure peak systolic valvular gradient $<25 \mathrm{mmHg}$.

\section{References}

1. Hong D, Qian MY, Zhang ZW, Wang SS, Li JJ, et al. (2017) Immediate therapeutic outcomes and medium-term follow-up of percutaneous balloon pulmonary valvuloplasty in infants with pulmonary valve stenosis: a single-center retrospective study. Chin Med J 130(23): 2785-2792.

2. Lanjewar C, Phadke M, Singh A, Sabnis G, Jare M, et al. (2017) Percutaneous balloon valvuloplasty with Inoue balloon catheter technique for pulmonary valve stenosis in adolescents and adults. Indian heart J 69(2): 176-181.

3. Merino-Ingelmo R, Santos-de Soto J, Coserria-Sánchez F, DescalzoSeñoran A, Valverde-Pérez I (2014) Long-term results of percutaneous balloon valvuloplasty in pulmonary valve stenosis in the pediatric population. Rev Esp Cardiol (Engl Ed), 67(5): 374-379.

4. Holzer RJ, Gauvreau K, Kreutzer J, Trucco SM, Torres A, et al. (2012) Safety and efficacy of balloon pulmonary valvuloplasty: a multicenter experience. Catheter Cardiovasc Interv 80(4): 663-672.

5. Parent JJ, Hoyer MH (2014) Delayed success of balloon dilation for coexisting pulmonary valve stenosis and sinotubular narrowing. Congenital Heart Dis 9(3): 216-220.
6. Kan JS, White Jr RI, Mitchell SE, Gardner TJ (1982) Percutaneous balloon valvuloplasty: a new method for treating congenital pulmonary-valve stenosis. N Engl J Med 307(9): 540-542.

7. Kaul UA, Singh B, Tyagi S, Bhargava M, Arora R, et al. (1993) Long-term results after balloon pulmonary valvuloplasty in adults. Am Heart J 126(5): 1152-1155.

8. Maostafa BA, Seyed-Hossien M, Shahrokh R (2013) Long-term results of balloon pulmonary valvuloplasty in children with congenital pulmonary valve stenosis. Iran J pediatr 23(1): 32-36.

9. Chen CR, Cheng TO, Huang T, Zhou YL, Chen JY, et al. (1996) Percutaneous balloon valvuloplasty for pulmonic stenosis in adolescents and adults. N Engl J Med 335(1): 21-25.

10. Kan JS, White Jr RI, Mitchell SE, Anderson JH, Gardner TJ (1984) Percutaneous transluminal balloon valvuloplasty for pulmonary valve stenosis. Circulation 69(3): 554-560.

11. Idrizi S, Milev I, Zafirovska P, Tosheski G, Zimbakov Z, et al. (2015) Interventional treatment of pulmonary valve stenosis: a single center experience. Open Access Maced J Med Sci 3(3): 408.

12. Arendrup HC, Kruse-Andersen S, Alstrup P (1983) Regression of infundibular hypertrophy after pulmonary valvulotomy without myocardial resection. Scand J Thorac Cardiovasc Surg 17(3): 243-248.

13. Fawzy ME, Hassan W, Fadel BM, Sergani H, El Shaer F, et al. (2007) Long-term results (up to 17 years) of pulmonary balloon valvuloplasty in adults and its effects on concomitant severe infundibular stenosis and tricuspid regurgitation. American Heart J 153(3): 433-438.

14. Fawzy ME, Galal O, Dunn B, Shaikh A, Sriram R, et al. (1990) Regression of infundibular pulmonary stenosis after successful balloon pulmonary valvuloplasty in adults. Cathet Cardiovasc Diagn 21(2): 77-81.

15. Thapar MK, Rao PS (1989) Significance of infundibular obstruction following balloon valvuloplasty for valvar pulmonic stenosis. American Heart J 118(1): 99-103.

16. Romeih S, Kroft LJ, Bokenkamp R, Schalij MJ, Grotenhuis H, et al. (2009) Delayed improvement of right ventricular diastolic function and regression of right ventricular mass after percutaneous pulmonary valve implantation in patients with congenital heart disease. Am Heart J 158(1): 40-46.

17. Luijnenburg SE, de Koning WB, Romeih S, van den Berg J, Vliegen HW, et al. (2012) Exercise capacity and ventricular function in patients treated for isolated pulmonary valve stenosis or tetralogy of Fallot. Int J Cardiol 158(3): 359-363.

18. Walker CP, Bateman CJ, Rigby ML, Brookes CI (2001) Acute pulmonary edema after percutaneous balloon valvuloplasty for pulmonary valve stenosis. J Cardiothorac Vasc Anesth15(4): 480-482.

19. Rao PS (2007) Percutaneous balloon pulmonary valvuloplasty: state of the art. Catheter Cardiovasc Interv 69(5): 747-763. 
This work is licensed under Creative Commons Attribution 4.0 License

DOI: 10.19080/JOCCT.2021.17.555951

\section{Your next submission with Juniper Publishers} will reach you the below assets

- Quality Editorial service

- Swift Peer Review

- Reprints availability

- E-prints Service

- Manuscript Podcast for convenient understanding

- Global attainment for your research

- Manuscript accessibility in different formats

( Pdf, E-pub, Full Text, Audio)

- Unceasing customer service

Track the below URL for one-step submission https://juniperpublishers.com/online-submission.php 